\title{
Numerical modelling based rock load height estimation at the goaf edge in a mechanised depillaring panel
}

\author{
Sahendra Ram, Rakesh Kumar, Ashok Kumar \\ Rajendra Singh \\ CSIR-CIMFR \\ Dhanbad, India \\ sahendra18@gmail.com
}

\author{
Dheeraj Kumar \\ Indian Institute of Technology (ISM) \\ Dhanbad, India
}

\begin{abstract}
Presence of different openings along the extraction line (goaf edge) in a mechanised depillaring (MD) panel provides an easy path for the goaf to encroach the working area during caving. A number of continuous miner based MD operations are adopted in Indian coalfields in last thirteen years, where roof bolt-based breaker line supports (RBBLS) is used to restrict the goaf encroachment. Different field studies by CSIR-CIMFR found that the performance of a RBBLS is significantly influenced by extension of spalling in coal pillars/fenders at the goaf edge. Development of higher induced stresses around the goaf edge during a MD operation creates the spalling in natural supports resulting a dilution in its competency at the goaf edge. It is observed that the RBBLS works satisfactorily under the shadow of stable natural supports only. Accordingly, the field studies have found that the positions of the RBBLS at the goaf edge need to be adjusted as per expected extent of the spalling. Under these conditions, estimation of rock load height $(\mathrm{RLH})$ with respect to proposed position of a RBBLS at the goaf edge is a difficult task in the field.
\end{abstract}

Therefore, a laboratory study, based on numerical modelling, is done using the FLAC3D package. The elastic model incorporating the Sheorey's failure criterion for the rock mass is used to analyse the rock mass behaviour at the goaf edge. Here, a criterion of 1.5 safety factor is used to obtain the RLH value. It is found that the value of RLH gets almost saturated after $2 \mathrm{~m}$ out-bye from the goaf edge for the considered site conditions. Therefore, an attempt is made to estimate the RLH at three positions $0 \mathrm{~m}, 1 \mathrm{~m}$ and $2 \mathrm{~m}$ out-bye from the goaf edge. This parametric study is conducted with a variation in depth of cover from $100 \mathrm{~m}$ to $450 \mathrm{~m}$ and rock mass rating from 20 to 70 . This study in the laboratory supported the field observations that a RBBLS works satisfactorily under the shadow of stable natural supports. A comparison of the RLH values for different selected positions of the RBBLS provided an idea to decide its suitable position of the RBBLS for a given site conditions. Discussing important findings of the field studies, this paper presents results of the numerical modelling for estimating the RLH at the goaf edge. Strength and weaknesses of this study for the design of a RBBLS are presented on the basis of a simple analysis of the simulation results.

Keywords-mechanised depillaring (MD); roof bolt-based breaker line supports (RBBLS); goaf encroachment; rock load height (RLH); numerical modelling; spalling.

\section{INTRODUCTION}

Slicing of a coal pillar/fender during the MD operation is an important mining activity, which is done under the protection of RBBLS in an opening at the goaf edge and a rib against the goaf. The RBBLS works efficiently under the shadow of stable ribs [1] and facilitates caving inside the goaf. An understanding of rib mechanics is vital for a design of the suitable RBBLS to improve efficiency of the MD operation. Further, RLH at the goaf edge is an important issue to decide the length of bolts for a RBBLS. However, the conditions in and around a goaf edge remain challenging due to the strong influence of the goafing phenomenon and creation of asymmetrical and complex underground mining structures.

A widely practiced empirical relationship [2] to design support in the underground openings is valid for development workings (bord \& pillar method) in Indian coalfields. Other relationships $[3,4]$ for estimation of required support density at the goaf edge may be applicable for the conventional depillaring only. In general, there is no design norm available for the design of RBBLS in a MD panel. Applications of RBBLS at different MD operations in Indian coalfields show intermediate results [5], which attracts an investigation for a design of the RBBLS. Strata mechanics studies by CSIR-CIMFR at different MD operations noticed that the performance of a RBBLS changes with the variations in the value of mining induced stress over the natural supports at the goaf edge. Extent of the side spalling/loosening due to the higher value of mining induced stress under different geo-mining conditions is observed up to $2 \mathrm{~m}$ at the goaf edge [6]. Field observations found that the depth of cover and nature of overlying strata are two major factors $[7,8]$ responsible for the mining induced stress which further affects the rib design too.

A systematic parametric study in field for the estimation of RLH at the goaf edge is difficult. Therefore, on the basis of the results of field studies, a detailed investigation is conducted in laboratory on simulated models for the existing range of geo-mining conditions of Indian coalfields. FLAC3D [9] is used for the simulation in association with the available empirical formulations for Indian coalfields. 
Using indigenously developed rock mass failure criterion [10], an analysis of safety factors for different site conditions of a MD operation on simulated models provided responses of mining structures for the RBBLS design. Observed contours of the safety factor (up to 1.5) are used to examine the RLH at different position at the goaf edge on simulated models. Considering the issues with rib and RBBLS design for $\mathrm{MD}$, an attempt is made in this paper to provide rib mechanics and RLH estimation with respect to nature of immediate roof and depth of cover. The estimated RLH also provided an idea of effective positioning of a RBBLS at the goaf edge for the given site conditions.

\section{NUMERICAL MODELLING}

Numerical modelling is a good techniques to simulate geo-mining conditions of a mine site for rock mechanics investigations in and around the goaf edge [3,11,12]. As per existing experience of CSIR-CIMFR, the investigation is done using FLAC3D package, which adopts finite difference method. Rock mass failure at the goaf edge can be observed using different models but elastic model is found to be more representative [13] due to development of maximum elastic stress. The elastic model of FLAC3D, incorporating the Sheorey failure criterion [10] for the rock mass is used for this study. Basically, this criterion uses the 1976 version of rock mass rating (RMR) of Bieniawski [14] for reducing the laboratory strength parameters to give the corresponding rock mass values. The same failure criterion using CMRI RMR (instead of Bieniawski RMR) by different Indian researchers [3] found to be equally correct for a rock mechanics study in Indian conditions. This criterion is defined as:

$$
\begin{gathered}
\sigma_{1}=\sigma_{\mathrm{cm}}\left(1+\frac{\sigma_{\mathrm{g}}}{\sigma_{\mathrm{mm}}}\right) \bar{D}_{\mathrm{m}} \mathrm{MPa} \\
\sigma_{\mathrm{mm}}=\sigma_{\mathrm{c}} \exp \left(\frac{R M R-100}{20}\right) \mathrm{MPa} \\
\sigma_{\mathrm{tm}}=\sigma_{\mathrm{t}} \exp \left(\frac{R M R-100}{27}\right) \mathrm{MPa}- \\
b_{\mathrm{m}}=b^{\text {RMA } / 100} ; b_{m}<0.95-
\end{gathered}
$$

where, $\sigma 1$ is tri-axial strength of rock mass or major principal stress in $\mathrm{MPa}, \sigma 3$ is confining stress or minor principal stresses in $\mathrm{MPa}, \sigma \mathrm{c}$ is compressive strength of intact rock in $\mathrm{MPa}$, $\sigma \mathrm{t}$ is tensile strength of intact rock in $\mathrm{MPa}, \mathrm{b}$ is exponent of intact rock (0.5), which controls the curvature of tri-axial curve, $\sigma_{\mathrm{cm}}$ is compressive strength of rock mass in $\mathrm{MPa}$. In the above equations, the subscript $\mathrm{m}$ stands for the rock mass. The factor of safety is defined as:

$$
S F=\frac{\sigma_{1}-\sigma_{3 i}}{\sigma_{1 i}-\sigma_{3 i}} ; \text { when }-\sigma_{3 i}>\sigma_{t m^{-}}
$$

Otherwise, it can be written as follows.

$$
S F=\frac{\sigma_{\mathrm{rm}}}{-\sigma_{3 i}}
$$

Where, $\sigma 1 \mathrm{i}$ is induced major principle stress in $\mathrm{MPa}, \sigma 3 \mathrm{i}$ is induced minor principle stress in $\mathrm{MPa}$.

Taking help of the site conditions of a studied site in field, a model of $252 \mathrm{~m}$ in length \& width and $115 \mathrm{~m}$ in height is developed (Fig. 1) for the study. Considering hardware constraints of a computer like memory, runtime and the effect on overlying strata up to 15 times of working height [15], only $59 \mathrm{~m}$ of roof and $50 \mathrm{~m}$ of floor have been modelled. The boundary around the modelled panel has been kept as $51 \mathrm{~m}$. The size of pillar is kept as $30 \mathrm{~m} \mathrm{x} 30 \mathrm{~m}$ (corner to corner). Width and height of gallery is fixed at $6 \mathrm{~m}$ and $4 \mathrm{~m}$ respectively.

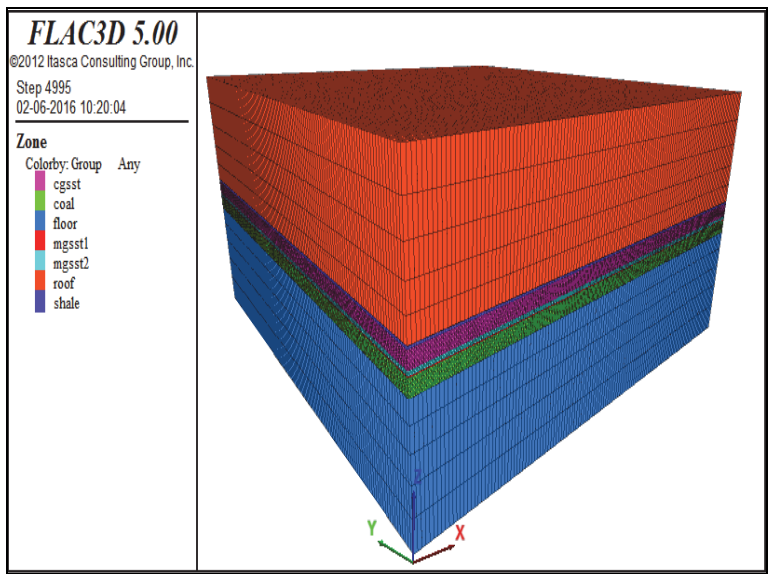

Fig. 1. Block formation for the considered site in FLAC3D (cgsst=course grained sandstone, mgsst=-medium grained sandstone)

A truncated load $(0.025 \mathrm{x}$ depth of cover, $\mathrm{MPa})$ for the un-modelled portion of the overlying strata is applied over the model. The sides and bottom boundaries of the model are fixed and the top one is kept free. The properties of rock mass to be used for the modelling are determined in laboratory using procured core samples from the field. Properties of different elements of reinforcement used in modelling are derived from the existing norms to design the reinforcement $[16,17]$. Grout stiffness and cohesive strength are determined as given in the manual of FLAC3D [9]. Considered properties of the rock mass and reinforcement materials are given in Table I.

\section{PARAMETRIC INVESTIGATION}

Initially, in situ model is simulated for every considered depth of cover followed by development through bord and pillar method. This model is then depillared (Fig. 2) and run for equilibrium without roof bolt-based breaker line support (WRBBLS) at the goaf edge. The simulation studies have revealed that induced stress near the goaf edge increases with span of hanging goaf. Considering the field studies, maximum value of mining induced stress observed during main fall and it usually happened after three rows of pillar extraction. Under the circumstances maximum deterioration 
in ribs/pillar is observed in terms of spalling, which affect the RLH at the goaf edge. Therefore, the RLH at the goaf edge is studied after 3rd row of extraction in the model at different depth of cover and under varying characteristics of the roof strata.

The parametric study for the RLH estimation was performed at three positions i.e. $0 \mathrm{~m}, 1 \mathrm{~m}$, and $2 \mathrm{~m}$ out-bye side from the goaf edge. The study was conducted for eight different depths of covers varying from $100 \mathrm{~m}$ to $450 \mathrm{~m}$. For each depth of cover, six different CMRI-RMR values from 20 to 70 were considered to evaluate RLH for the above mentioned three different positions, out-bye side of the goaf edge.

\section{STRATA MECHANICS AT GOAF EDGE}

A depillaring operation involves three important mining domains, which are: (a) active mining zone ahead of the goaf line, (b) goaf and (c) interface between (a) and (b) i.e. goaf edge. At the goaf edge, natural supports and applied support in the openings are important elements to restrict the goaf encroachment. Here, it is important to study the interaction between roof and pillars around the goaf edge under the existing site conditions of the MD. The range and value of different parameters considered for the parametric study are presented in Table II.

TABLE I. Properties Rock MASS AND REINFORCEMENT

\begin{tabular}{|c|c|c|}
\hline $\begin{array}{c}\text { Rockmass / } \\
\text { reinforcement }\end{array}$ & Parameter & Value \\
\hline \multirow{3}{*}{ Sandstone } & Young's Modulus(GPa) & 7 \\
\hline & Poisson Ratio, $v$ & 0.25 \\
\hline & Density $(\mathrm{kg} / \mathrm{m} 2)$ & 2500 \\
\hline \multirow{3}{*}{ Coal } & Young's Modulus(GPa) & 2 \\
\hline & Poisson Ratio & 0.25 \\
\hline & Density $(\mathrm{kg} / \mathrm{m} 2)$ & 1440 \\
\hline \multirow{3}{*}{ Shale } & Young's Modulus(GPa) & 5 \\
\hline & Poisson Ratio & 0.25 \\
\hline & Density $(\mathrm{kg} / \mathrm{m} 2)$ & 2500 \\
\hline \multirow{4}{*}{ Grout } & Grout stiffness per unit length $(\mathrm{N} / \mathrm{m} 2)$ & $2.94 \mathrm{e} 10$ \\
\hline & Grout cohesive strength $(\mathrm{N} / \mathrm{m})$ & $1.34 \mathrm{e} 6$ \\
\hline & Grout exposed perimeter $(\mathrm{m})$ & $8.95 \mathrm{e}-2$ \\
\hline & $\begin{array}{l}\text { Shear strength of grout/rock or } \\
\text { bolt/grout interface }(\mathrm{MPa})\end{array}$ & 15 \\
\hline \multirow{7}{*}{ Roof bolt } & Length $(\mathrm{m})$ & 2.4 \\
\hline & Diameter $(\mathrm{mm})$ & 22 \\
\hline & Cross sectional area $(\mathrm{m} 2)$ & $3.8 \mathrm{e}-4$ \\
\hline & Young's modulus (GPa) & 200 \\
\hline & Tensile Yield strength $(\mathrm{N})$ & $2.43 \mathrm{e} 5$ \\
\hline & Pretension $(\mathrm{N})$ & $2.94 \mathrm{e} 4$ \\
\hline & Length $(\mathrm{m})$ & 2.4 \\
\hline
\end{tabular}

TABle II. RANGe AND VALUES Of DifFERENT PARAMETERs CONSIDERED FOR THE SIMULATION STUDY

\begin{tabular}{|c|c|}
\hline Depth & CMRI-RMR \\
\hline $100 \mathrm{~m}$ & $20,30,40,50,60$ and 70 \\
\hline $150 \mathrm{~m}$ & $20,30,40,50,60$ and 70 \\
\hline $200 \mathrm{~m}$ & $20,30,40,50,60$ and 70 \\
\hline $250 \mathrm{~m}$ & $20,30,40,50,60$ and 70 \\
\hline $300 \mathrm{~m}$ & $20,30,40,50,60$ and 70 \\
\hline $350 \mathrm{~m}$ & $20,30,40,50,60$ and 70 \\
\hline $400 \mathrm{~m}$ & $20,30,40,50,60$ and 70 \\
\hline $450 \mathrm{~m}$ & $20,30,40,50,60$ and 70 \\
\hline
\end{tabular}

Generally, in the beginning of the pillar extraction, a beam of overlying strata (supported from all sides) is formed over the goaf. After a sufficient increase in the dimension of the goaf, the beam of roof strata fails and a cantilever is formed at the goaf edge. Now, splitting/slicing work for the progress of the depillaring is done under the cover of this cantilever. After creation of sufficient goaf span; goaf encroachment due to global strata movement is mainly controlled by competent pillars and fenders present at the goaf edge. Further, at the same time the pillars/fenders receive mining induced stress which causes spalling/loosening in the natural supports [18]. Slicing of a fender/pillar is done under the protection of rib and adjacent RBBLS against goaf. The left out ribs also work/perform like applied support for a depillaring operation [19] and its size is observed to be dependent upon nature of immediate roof strata [1]. The stable rib holds the RBBLS, which provides efficient slicing situation

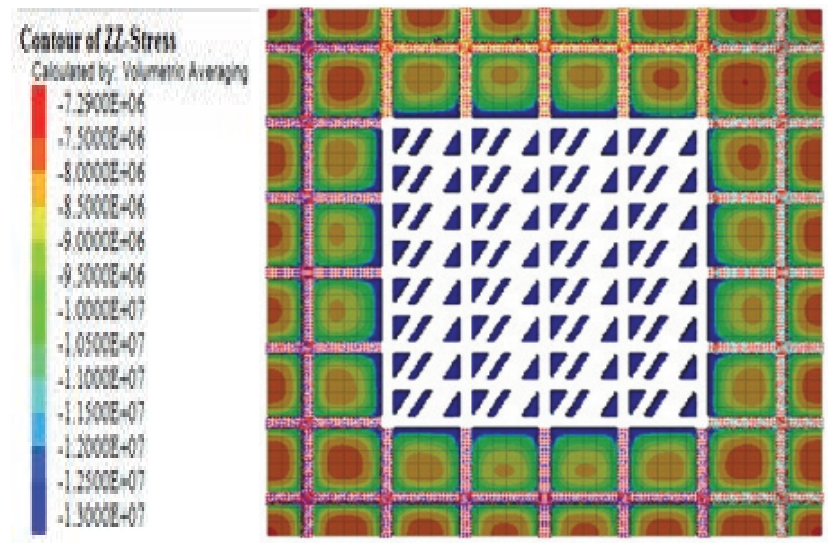

Fig. 2. Pillar extraction in a model.

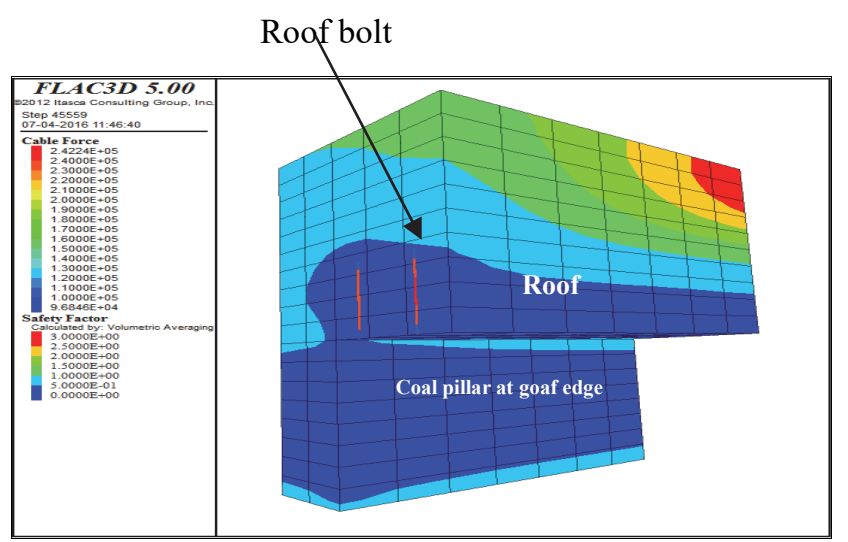

Fig. 3. Safety factor contour near the goaf edge without RBBLS.

Considering these consequences, depth of spalling in the natural support is considered for suitable design of rib for a given site conditions. Here, the rib controls the local instability in the lower horizon of the cantilever (to cover the span over the proposed slice for the depillaring) and prevent the goaf encroachment in the working slice. Stress concentrations over a rib are shown in Fig. 4 to visualise the effective position of RBBLS at the goaf edge. From the numerical study it is observed that around $2 \mathrm{~m}$ inside of coal 
pillar at the goaf edge is in tension or about to spall creating plastic zone at the periphery. In field, depth of spalling i.e. plastic zone in coal pillars has been found up to $2 \mathrm{~m}$ in outbye of the goaf edge during MD [18], which found to be in good agreement with the numerical simulation results.

\section{IMPORTANT FINDINGS}

The depth of cover influences RLH in two different ways. For RMR ranging from 20 to 50 , RLH reduces with increase in depth of cover up to $200 \mathrm{~m}$ for RMR 20 and 30. The RLH reduces only up to $150 \mathrm{~m}$ of depth for RMR 40 and 50. When depth of cover exceeds $200 \mathrm{~m}$, RLH starts increasing and, more or less, the same trend continues up to $450 \mathrm{~m}$. For the RMR 60 and 70, the RLH increases for the whole considered range of the depth of cover. There is a drop in the safety factor of the surrounding natural supports with the increase in depth of cover (200 $\mathrm{m}$ and more), which might have diluted the efficacy of RBBLS too. RLH at $0 \mathrm{~m}$ out-bye is observed from $2.7 \mathrm{~m}$ to $8 \mathrm{~m}$ at the goaf edge for RMR 20 to 60, which is higher than the actual bolt length of the RBBLS [5] installed in fields. Similarly, at $1 \mathrm{~m}$ out-bye from the goaf edge, RLH is observed from 2.5 to $5.8 \mathrm{~m}$ for RMR 20 to 50 which is difficult to be supported by $2.4 \mathrm{~m}$ bolt length of RBBLS.

\section{Position of RBBLS at $2 \mathrm{~m}$}

\section{Spalling up to $2 \mathrm{~m}$ out-bye from the goaf edge}

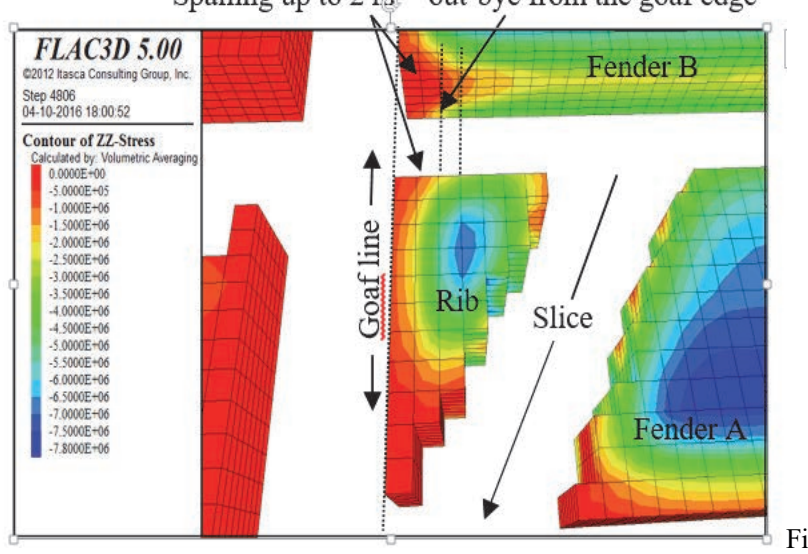

g. 4 - A typical behaviour of rib at the goaf edge.

The RLH observed at $2 \mathrm{~m}$ out-bye from the goaf edge in the models are given in Table III. The RMR of immediate roof strata, where continuous miner based MD operation practiced in Indian coalfields, is observed to be varying from 42 to 62 except at Tandsi mine. At all these mines (except Tandsi) it is found that the RLH is below $2.4 \mathrm{~m}$ [20]. The roof strata of Tandsi are highly laminated and CMRI-RMR is 36 only. A detailed analysis is done and developed an empirical formulation [20] for RLH, which is found to be in good agreement with the field observation (Table IV).

The conducted studies in laboratory and field found that extension of side spalling/loosening in coal pillars/fenders/ribs at the goaf edge influences RBBLS performance. It is also observed that when the extent of the side spalling crosses the position of a RBBLS then it cease to work satisfactorily during the caving. Otherwise, generally, it remains intact at the time of caving. Thus, it can be concluded that RBBLS works effectively only under the shadow of stable pillars/fenders/ribs at the goaf edge.

The side spalling depends upon the amount of induced stress developed over the natural support at the goaf edge. In case of easily to moderately caveable overlying strata, spalling gets extended up to $1 \mathrm{~m}$ out-bye from the goaf edge under shallow depth of cover $(<200 \mathrm{~m})$. The spalling zone increases up to $2 \mathrm{~m}$ out-bye from the goaf edge in case of roof with difficult in caving at deeper cover $(200 \mathrm{~m}$ to 400 $\mathrm{m})$.

The width of the panel also influences development of the side spalling in case of difficult roof conditions. Under such conditions, panel situated at higher depth of cover $(>200 \mathrm{~m})$ experiences more spalling in coal pillars, especially in the middle portion of the goaf edge. However under such conditions, a panel situated at shallow depth of cover $(<200$ $\mathrm{m})$ and width less than $150 \mathrm{~m}$ did not encounter any considerable value of the side spalling. In case of easily to moderately caveable roof strata, regular caving is experienced during the MD operation. Under such conditions, no significant effect of width of the panel is observed due to regular caving of overlying strata.

High capacity, pre-tensioned, stiff and resin grouted roof bolts of $2.4 \mathrm{~m}$ in length is suitable for RMR 42 to 70 at 100 $\mathrm{m}$ to $400 \mathrm{~m}$ depth of cover. For lower value of RMR $(<42)$ bolt length of RBBLS is to be 3-6 m. Position of RBBLS at the goaf edge is to be kept $1 \mathrm{~m}$ out-bye for easily to moderately caveable roof strata and $2 \mathrm{~m}$ out-bye for the strata which are difficult to cave.

TABle III. Rock LOAD HEIGHT OBSERVED From THE Simulation Studies AT 2 M OUT-Bye From ThE GOAF EDGE

\begin{tabular}{|l|l|l|l|l|l|l|}
\hline \multirow{2}{*}{$\begin{array}{c}\text { Depth of } \\
\text { cover (m) }\end{array}$} & \multicolumn{7}{|c|}{ Rock Load Height (m) } \\
\cline { 2 - 7 } & \multicolumn{6}{|c|}{ Rock Mass Rating } \\
\cline { 2 - 7 } & 20 & 30 & 40 & 50 & 60 & 70 \\
\hline 100 & 4.8 & 4 & 3.3 & 2.5 & 1.4 & 0 \\
\hline 150 & 4 & 3.6 & 3 & 2.4 & 1.5 & 0 \\
\hline 200 & 3.9 & 3.5 & 3 & 2.4 & 1.7 & 0.7 \\
\hline 250 & 3.8 & 3.5 & 3 & 2.4 & 1.6 & 0.7 \\
\hline 300 & 4 & 3.6 & 3 & 2.4 & 1.8 & 0.9 \\
\hline 350 & 4 & 3.9 & 3.2 & 2.5 & 1.8 & 0.9 \\
\hline 400 & 4.1 & 3.8 & 3.5 & 2.6 & 1.9 & 1.2 \\
\hline 450 & 4.2 & 3.8 & 3.5 & 2.8 & 1.9 & 1.3 \\
\hline
\end{tabular}

TABLE IV. A COMPARISON BETWEEN ACTUAL BOLT LENGTH USED IN RBBLS AND OBTAINED RLH FROM MODELLING

\begin{tabular}{|l|l|l|l|l|}
\hline Name of mine & \multicolumn{1}{|c|}{$\begin{array}{c}\text { Depth } \\
(\mathbf{m})\end{array}$} & RMR & $\begin{array}{c}\text { Applied bolt } \\
\text { length (m) }\end{array}$ & $\begin{array}{c}\text { RLH } \\
{[\mathbf{2 1}]}\end{array}$ \\
\hline GDK 11 & 312 & 47 & 2.4 & 2.26 \\
\hline Pinoura & 120 & 42 & 2.4 & 2.31 \\
\hline Anjan Hill & 125 & 52 & 2.4 and 1.8 & 1.79 \\
\hline Jhanjra & 120 & 55 & 2.4 & 1.67 \\
\hline Tandsi & 260 & 36 & 5 & 3.05 \\
\hline VK 7 & 377 & 62 & 2.4 & 1.66 \\
\hline
\end{tabular}

The studies confirmed that the bolt density in RBBLS give significant improvement for safety factor of the roof strata at the goaf edge. On the basis of field and laboratory results, it may be concluded that RBBLS is to be installed at $0.75 \mathrm{~m}$ 
and $1 \mathrm{~m}$ grid patterns at depth of cover more than $200 \mathrm{~m}$ and less than $200 \mathrm{~m}$ respectively.

\section{CONCLUSIONS}

Application of the RBBLS in a mechanised depillaring in Indian coalfields is an interesting technical accomplishment. Its performance in field is observed to be intermediate due to the positional effect. Spalling in natural support at the goaf edge due to mining induced stress is the main contributing factor for the positional effect on the RBBLS and it is site specific. RLH estimation through numerical modelling's result provided significant information for designing the RBBLS. High value of RLH is noticed at $0 \mathrm{~m}$ from goaf edge for all considered depths of cover. It is found that RBBLS does not work at all if installed right at the goaf edge. For a better performance, position of RBBLS is shifted towards out-bye side of the goaf edge in the field as per depth of cover and RMR. This shifting of the RBBLS provided better results in the field. Further, the value of RLH falls below $2.4 \mathrm{~m}$ and gets almost saturated after $2 \mathrm{~m}$ out-bye from the goaf edge. Therefore, position of the RBBLS is thought to be varying within $2 \mathrm{~m}$ from the goaf edge only, which is in tune with the required safety and conservation of coal too.

\section{ACKNOWLEDGEMENT}

The authors are obliged to Dr. P. K. Singh, Director, CSIR-CIMFR, for his permission to publish this paper. Dr. Arun Kr. Singh and Mr. Amit Kumar Singh of Strata Mechanics Section provided considerable help in field work are really acknowledged. The co-operation provided by the management of different coal companies during the field study is thankfully acknowledged. The views expressed in the paper are those of the authors, and not necessarily of the institute to which they belong.

\section{REFERENCES}

[1] R. Singh, A. Kumar, A. K. Singh, J. Coggan, and S. Ram, "Rib/snook design in mechanised depillaring of rectangular/square pillars," Int J Rock Mech Min Sci, Vol.84, pp. 19-29, 2016.

[2] V. Venkateswarlu, A. K. Ghose and N. M. Raju, "Rock mass classification for design of roof support - A statistical evaluation of parameters," Min Sc Tech, Vol. 8, pp. 97-107, 1989.

[3] A. Kushwaha, S. K. Singh, S. Tewari and A. Sinha, "Empirical approach for designing of support system in mechanized coal pillar extraction," Int J Rock Mech Min Sci, Vol. 47, pp. 1063-78, 2010.

[4] A. K. Singh, A. Sinha, A. Paul and K. Saikia, "Geotechnical investigation for support design in depillaring panels in Indian coalmines," Journal of Scientific \& Industrial Research, Vol. 64, pp. 358-363, 2005.

[5] S. Ram, D. Kumar, P. Konicek, A. K. Singh, R. Kumar, A. K. Singh and R. Singh, "Rock mechanics studies during continuous miner based coal pillar extraction in Indian coalfields," Transactions (April 2014-March 2015): a technical publication of the MGMI, Kolkata, India, Vol. 111, pp. 89-114, 2015.

[6] S. Ram, A. K. Singh, D. Kumar and R. Singh, "Design of Roof Bolt based Breaker Line Support in a Mechanised Depillaring Panel," In: Proceedings of 35th International Conference on Ground Control in Mining, 26-28 July 2016, Morgantown, WV, USA, pp. 155-61.
[7] R. Singh, T.N. Singh and B. B. Dhar, "Coal pillar loading for shallow mining conditions," Int J Rock Mech Min Sci Geomechs Abst, Vol. 33, no. 8, pp. 757-68, 1996.

[8] R. Singh, P. K. Mandal, A. K. Singh and T. N. Singh, "Cable bolting based mechanised depillaring of a thick coal seam," Int J Rock Mech Min Sci, Vol. 38, no. 2, pp. 245-57, 2001.

[9] Itasca. FLAC3D (Fast Lagrangian Analysis of Continua in 3 Dimensions), Version 5.0, Itasca Consulting Group Inc., Minneapolis, Minnesota, 55401, USA, 2012.

[10]P. R. Sheorey, "Empirical rock failure criteria," Rotterdam, Balkema, pp. 176, 1997.

[11]A. K. Verma and D. Deb, "Numerical analysis of the interaction between hydraulic powered support and surrounding rock strata at Indian longwall faces," 12thInternational Conference of International Association for Computer Methods and Advances in Geomechanics (IACMAG), Goa, India, pp. 394-402, 1-6 October, 2008,

[12] H. Yavuz, "An estimation method for cover pressure re-establishment distance and pressure distribution in the goaf of longwall coal mines," International Journal of Rock Mechanics and Mining Sciences, Vol. 41, pp. 193-205, 2004.

[13] H. Basarir, I Oge Ferid and Aydin O, "Prediction of the stresses around main and tail gates during top coal caving by 3D numerical analysis," International Journal of Rock Mechanics and Mining Sciences, Vol. 76, pp. 88-97, 2015.

[14]Z. T. Bieniawski, "Rock mass classifications in rock engineering," In: Exploration for Rock Engineering, Editors: Z. T. Bieniawski, Vol. 1, Balkema, Rotterdam, pp. 97-106, 1976.

[15]A. K. Singh, "Studies of mining induced vertical stress ahead of a depillaring face in Indian geo-mining conditions," Ph.D. thesis submitted to Bengal Engineering and Science University, Shibpur, Howrah-711103, 2010.

[16]DGMS Circular, "Standard Components and Properties required for Resin Capsules to be used as grouting material for Roof bolting in Mines. No. DGMS/S\&T/Tech. Cir. (Approval) No.10," Dhanbad, 13th July, 2009.

[17] DGMS Circular, "Standard Components and Properties of Steel Roof Bolts to be used in Mines No. DGMS/S\&T/Tech. Cir. (Approval)," Dhanbad, the 3rd June, 2010.

[18] S. Ram, A. K. Singh, D. Kumar, R. Singh, "Design of Roof Bolt based Breaker Line Support in a Mechanised Depillaring Panel," In: Proceedings of 35th International Conference on Ground Control in Mining. Morgantown, WV, USA, pp. 155-61, 26-28 July 2016.

[19]C. Mark, J. C. Zelanko, "Sizing of Final Stumps for Safer Pillar Extraction. Proceedings," 20th International Conference On Ground Control in Mining, Morgantown, WV, pp. 59-66, 2001.

[20] S. Ram, "A study of roof-pillar interaction for an efficient breaker line design during Mechanised depillaring," Ph.D. thesis submitted to Indian Institute of Technology (Indian School of Mines) Dhanbad, 2016. 